\title{
A multi-objective assessment of the effect of solar PV array orientation and tilt on energy production and system economics
}

\author{
Joshua D. Rhodes ${ }^{\mathrm{a}, *}$, Charles R. Upshaw ${ }^{\mathrm{b}}$, Wesley J. Cole ${ }^{\mathrm{c}}$, Chris L. \\ Holcomb $^{\mathrm{d}}$, Michael E. Webber ${ }^{\mathrm{b}, \mathrm{e}, * *}$ \\ ${ }^{a}$ Department of Civil, Architectural and Environmental Engineering, The University of \\ Texas at Austin, 301 E Dean Keeton St. Stop C1752, Austin, TX 78712-1094 \\ ${ }^{b}$ Department of Mechanical Engineering, The University of Texas at Austin, 204 E. \\ Dean Keeton Street, Stop C2200, Austin, Texas 78712-1591 \\ ${ }^{c}$ Department of Chemical Engineering, The University of Texas at Austin, 200 E. Dean \\ Keeton St. Stop C0400, Austin, Texas 78712-1591 \\ ${ }^{d}$ The Butler Firm, 1601 Rio Grande St \#331, Austin, TX 78701 \\ ${ }^{e}$ Energy Institute - The University of Texas at Austin, 2304 Whitis Ave Stop C2400 \\ Austin TX 78712-1718
}

\begin{abstract}
This analysis considers the effect of the placement (azimuth and tilt) of fixed solar PV systems on their total energy production, peak power production, and economic value given local solar radiation, weather, and electricity market prices and rate structures. This analysis details a model that was used to calculate the output of solar PV systems across a range of azimuths and tilts to find the energetically and economically optimal placement. The result of this method, which concludes that the optimal placement can vary with a
\end{abstract}

\footnotetext{
${ }^{*}$ Corresponding author

** Principal corresponding author Email addresses: joshdr@utexas.edu (Joshua D. Rhodes), crupshaw@gmail.com (Charles R. Upshaw), wesleycole@gmail.com (Wesley J. Cole), chris. lee.holcomb@gmail.com (Chris L. Holcomb), webber@mail.utexas.edu (Michael E. Webber)
} 
multitude of conditions, challenges the default due-south placement that is conventional for typical installations. We found that for Austin, TX the optimal azimuth to maximize energy production is about $187-188^{\circ}$, or $7-8^{\circ}$ west of south, while the optimal azimuth to maximize economic output based on the value of the solar energy produced is about $200-231^{\circ}$ or $20-51^{\circ}$ west of south. The differences between due south (which is the conventional orientation) and the optimal placement were on the order of $1-7 \%$. Solar PV arrays that are not constrained on their placement, such as ground mounted arrays, could possibly increase overall production or the value of that production at no additional installation cost by a slight rotation from the traditional orientation of due south. The model is then extended to consider 1,020 locations across the United States that have Typical Meteorological Year (TMY) data to provide a spatial view of optimal solar placements across the country. For the rest of the US we found that for most locations the energetically optimal solar PV azimuth is within $10^{\circ}$ of south. Considering the temporal value of the solar energy produced from spatially-resolved market conditions derived from local time-of-use rates, the optimal placement shifts to a west-of-south azimuth in attempt to align solar energy production with higher afternoon prices and higher grid stress times. There are some locations particularly on the west coast that have west-of-south energy optimal placements, possibly due to typical morning clouds or fog. Further solar considerations, such as maximum peak alignment also have the potential to influence solar placement. These results have the potential to be significant for solar PV installations: utilities might alter rate structures to encourage solar generation that is more coincident with peak demand, utilities might also use west-of-south 
solar placements as a hedge against future wholesale electricity price volatility, building codes might encourage buildings to match roof azimuths with local optimal solar PV generation placements, and calculations of the true value of solar in optimal and non-optimal placements can be more accurate. Keywords:

optimal solar placement, maximum value, peak power demand

1 1. Introduction

2 This analysis considers the effect of the placement (azimuth and tilt) of 3 fixed solar PV systems on their total energy production, peak power pro4 duction, and the economic value of that energy production. Solar energy 5 production is important for a multitude of reasons including reduced carbon 6 emissions; a fuel source that is free, renewable, domestic and distributed; its 7 contributions for energy equity, and because the prices of solar panels are s falling [1-6]. As a consequence of all these factors, in the US, solar instalplants in the mid-future [7]. Thus, analytical methods - such as the one developed herein - that optimize the usefulness of those installations are valuable.

There have been many investigations into the optimal tilt for solar PV systems. These investigations were summarized in a recent review by Yadav and Chandel [8] and therefore will not be reproduced here. However, it is important to note that many of these analyses consider solar energy production assuming that a southern azimuth (in the northern hemisphere) is optimal for energy production. While the south-orientated rule-of-thumb 
might be best for completely clear skies, non-uniform, temporal meteorological conditions such as fog or clouds, environmental conditions such as smog, and geographic features such as mountains can block solar radiation and reduce solar panel output at different times of the day and change the optimal orientation of the panels [9, 10]. Additionally, solar PV power output is a function of panel temperature [11], so dry bulb temperature fluctuations and wind speed (because of convective heating or cooling) alter PV electricity production. Lave and Kleissl [10] determined the optimal tilt and azimuth angles for the continental United States using a high resolution grid $\left(0.1^{\circ}\right.$ by $0.1^{\circ}$ ). They considered solar radiation effects, such as cloud cover, but not temperature effects.

Another consideration for optimal PV orientation is the value of the electricity generated. Because solar energy production does not always precisely align with maximum electricity grid load, even placements that might be non-optimal from an energy production basis might be optimal on an economic or peak power production basis [12 14]. Luoma et al. [15] used dayahead market electricity prices to determine optimal solar PV orientations in California. Their work found that the market electricity prices shifted the optimal orientation of some arrays further west of south.

This analysis extends the body of knowledge by estimating optimal solar orientations for 1,020 U.S. locations while considering the effects of dry bulb temperature, wind speed, and actual (i.e., not clear-sky) solar radiation. This analysis also considers the value of solar energy produced by using time-ofuse rates throughout the continental US as a proxy for average local grid conditions. This work differs from similar solar placement work [10] in that 
44

\section{Methods}

This analysis uses available solar insolation and electricity price data to 1) determine the insolation on a given plane (with available solar radiation tools), 2) build a residential system-based solar PV production model, 3) estimate the total energy, power, and economic impacts of system azimuth and tilt (placement) for Austin, TX, 4) extend the analysis to other locations across the US, and 5) explore the peak power production and solar ramp rate implications of varying solar placements using the aforementioned datasets. The workflow is given in Figure 1.

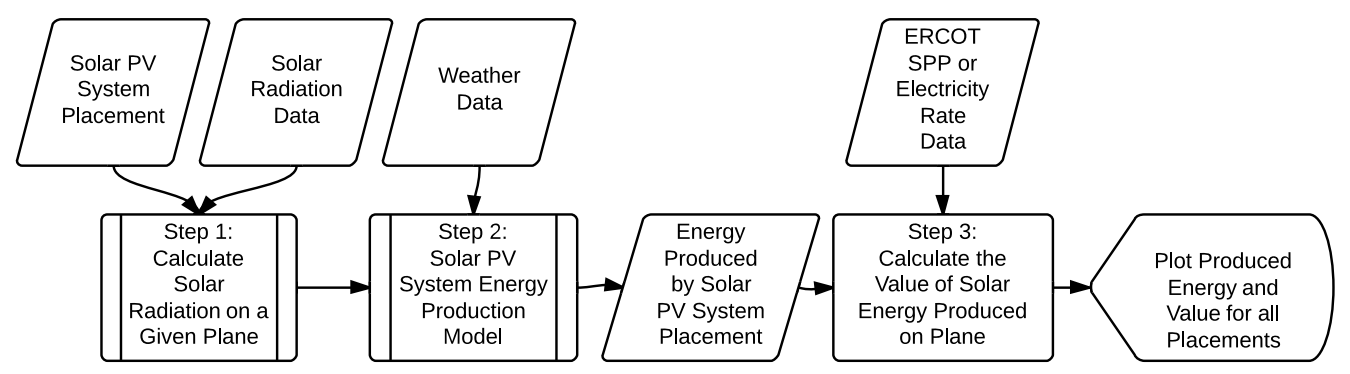

Figure 1: This diagram shows the process of modeling the energy and the value of energy produced from various solar placements. 


\subsection{Determining incident solar insolation on a plane}

Because the goal of this analysis is to determine the value of various solar placements, it was necessary to calculate the incident solar radiation for multiple azimuths and tilts. There have been many investigations into models that simulate total solar radiation on a tilted plane from that of the horizontal, and readers are directed to texts and reviews of those studies [16, 17. There are three main components of solar radiation on a surface, 1) direct beam, 2) diffuse from the sky, 3) and the reflected from the ground [16]. Many models use the same methods for calculating the direct beam and reflected, but differ on methods of calculating incident diffuse from the sky. This analysis utilized the sola $R$ package of the $R$ language [18], which uses the diffuse model of Hay and Davies [19] with the the horizon brightness correction proposed by Reind et al. [20]. The total effective radiation on a tilted plane is given by Equation 1:

$$
I_{T}=B_{T}+R_{T}+D_{T}
$$

${ }_{11}$ where $I_{T}$ is the incident radiation on the tilted plane, $B_{T}$ is the beam radiation on the tilted plane given by Equation 2

$$
B_{T}=I_{B} R_{B}
$$

${ }_{3}$ where $I_{B}$ is the beam radiation on the horizontal plane, $R_{B}$ is the ratio of beam radiation on the tilted plane to that on a horizontal surface given by 
Equations 35 [17]:

$$
\begin{gathered}
R_{B}=\frac{\cos (\theta)}{\cos \left(\theta_{z}\right)} \\
\cos (\theta)=\sin (\delta) \sin (\phi) \cos (\beta)-\sin (\delta) \cos (\phi) \sin (\beta) \cos (\gamma) \\
+\cos (\delta) \cos (\phi) \cos (\beta) \cos (\omega)+\cos (\delta) \sin (\phi) \sin (\beta) \cos (\gamma) \cos (\omega) \\
+\cos (\delta) \sin (\beta) \sin (\gamma) \sin (\omega) \\
\cos \left(\theta_{z}\right)=\cos (\phi) \cos (\delta) \cos (\omega)+\sin (\phi) \sin (\delta)
\end{gathered}
$$

76 where $\delta$ is the declination, $\phi$ is the local latitude, $\beta$ is the tilt of the surface, ${ }_{77} \gamma$ is the surface azimuth angle, and $\omega$ is the hour angle.

${ }_{78} R_{T, i}$ is the reflected radiation on the tilted plane given by Equation 6 .

$$
R_{T}=\alpha I_{0} \frac{1-\cos (\beta)}{2}
$$

$$
D_{T, i}=D_{0}\left[\frac{1}{2}(1-\kappa)(1+\cos (\beta)) \times\left(1+\sqrt{\frac{B_{0}}{G_{0}}} \times \sin (\beta / 2)^{3}\right)+\kappa R_{B, i}\right]
$$


where $D_{0}$ is the diffuse radiation on the horizontal plane, $\kappa$ is the anisotropy index such that $\kappa=I_{B} / I_{0}$ where $I_{0}$ is the solar constant, $B_{0}$ is the beam irradiance on the horizontal surface, and $G_{0}$ is the global irradiance on the horizontal surface.

There are three sources of solar data used in this analysis, 1) actual measured data for Austin, 2) TMY data, and 3) clear-sky data. For Equations 1-7, in cases where the data were 'measured' data, the horizontal beam and the diffuse were directly measured from pyranometers located in Austin, TX. In cases where TMY data were utilized in this analysis, the diffuse horizontal data in the TMY data was used as the diffuse horizontal value in Equations 1- 7 and the beam horizontal value used is the difference between the global and diffuse horizontal values in the TMY data. In the case where the data used is the clear-sky data, the values were directly calculated.

\subsection{Solar PV System Energy Production Model}

To estimate AC solar PV electricity production from solar radiation on a plane, a solar PV energy production model was built. The overall model is given in Equations 8- 9:

$$
\begin{gathered}
P_{\text {out }, i}=\eta_{p v, i} \times \eta_{\text {inv }, i} \times \eta_{o t h e r} \times I_{T, i} \\
\eta_{p v, i}=\eta_{r e f}\left[1-\beta_{\text {ref }}\left[T_{a, i}-T_{r e f}+\left(T_{N O C T}-T_{a, N O C T}\right) \frac{I_{T, i}}{I_{N O C T}}\right]\right]
\end{gathered}
$$

where $P_{\text {out }, i}$ is the power output of the system in $\mathrm{W} / \mathrm{m}^{2}$ of PV array, $\eta_{p v, i}$ is the efficiency of the solar PV panels, $\eta_{i n v, i}$ is the efficiency of the (DCAC) solar inverter, $\eta_{\text {other }}$ are other (in this case constant) derate factors 
(mismatch, connections, wiring, etc., taken to be 0.93) associated with solar PV arrays, $I_{T, i}$ is the incident radiation on the tilted plane (Equation 1), $\eta_{\text {ref }}$ is the efficiency of the PV panels (taken to be $12 \%$ ), $\beta_{\text {ref }}$ is the temperature coefficient of the PV panels (taken to be $0.0045 \mathrm{~K}^{-1}$ ), $T_{a}$ is the ambient temperature, $T_{r e f}$ is the reference temperature of the $\mathrm{PV}$ panels $\left(25^{\circ} \mathrm{C}\right)$, $T_{N O C T}$ is the nominal operating cell temperature at operating test conditions, $T_{a, N O C T}$ is the ambient $\mathrm{NOCT}\left(20^{\circ} \mathrm{C}\right)$ and $I_{N O C T}$ is the incident radiation for the NOCT test, which is $800 \mathrm{~W} / \mathrm{m}^{2}$, for an overview of the NOCT equations, see Skoplaki and Palyvos [21], all (besides constants) at time $i$. The efficiency of the modeled inverter $\eta_{i n v, i}$ was modeled as a $6^{\text {th }}$ degree polynomial fit of a commercially available solar inverter (Power-One PVI-5000 [22]), scaled from a nominal $5 \mathrm{~kW}$ PV array of commercially available solar PV panels (Lumos LS250 [23]) to a per $\mathrm{m}^{2}$ of array. Note that the constants used in this analysis are average and thus the output might differ for other technologies, for example, thin film modules are less affected by temperature, so they might have more western optimum placements as they are able to hold closer to their rated efficiency as their temperature increases.

\subsection{Calculating the value and effect of solar placement}

After construction of the solar PV model based on meteorological, astronomical conditions, and assumed PV characteristics, a second model was developed to calculate the solar PV electricity produced from a solar PV system for any given placement, accommodating different tilts and azimuths. This model consisted of three steps. First, given a placement and the horizontal solar radiation values, it calculated the solar radiation on a plane. Second, using the solar PV model developed in Section 2.2 and weather data, it cal- 
culated the energy produced at that placement. The last step calculated the value of the energy produced using either local market conditions from the Electric Reliability Council of Texas (ERCOT) or local utility rates. ERCOT settlement point prices (SPP) are actual wholesale electricity market rates, available on a 15-minute interval, for the ERCOT grid (about $85 \%$ of Texas). ERCOT SPP data used in this analysis included ERCOT 2011 (the actual prices from 2011, averaged on the hour; 2011 was considered to be a scarcity year with higher than usual prices), ERCOT AVG (the average ERCOT price for 2011 - 2013, averaged on the hour), ERCOT AUCT (the actual ERCOT prices for the time of the measured Austin solar radiation data). Local utility rates were collected from the OpenEI utility rate database [24].

All possible combinations of azimuths ranging from $90^{\circ}$ (due east) to $270^{\circ}$ (due west) and tilts from $0^{\circ}$ (horizontal) to $45^{\circ}$ were used to calculate the solar insolation on the respective plane. These data were fed into the Solar PV Energy Production Model (Section 2.2), along with weather data to quantify the amount of energy produced over one year for that particular configuration. These data were then multiplied by the temporally corresponding ERCOT electricity market price (for the Austin specific analysis) or TOU rate data (for the national analysis) and summed to calculate the value of the solar energy produced as per Equation 10 .

$$
\text { Value }=\sum_{i}^{1 \text { year }} P_{\text {out }, i} \times \Delta t \times \text { Price }_{1, i}+P_{\text {out }, i} \times \text { Price }_{2, i}
$$

where $P_{\text {out }, i}$ is the power output of the solar PV system in $\mathrm{W}, \Delta t$ is the timestep, Price $_{1, i}$ is the economic price (ERCOT SPP or TOU rate, $\$ / \mathrm{kWh}$ ), and Price $_{2, i}$ is the price associated with reduction in overall demand charges for 
a commercial or industrial consumer that has the solar PV system behind the meter, all at time $i$. For industrial solar power plants, Price ${ }_{2, i}$ could also be used to estimate ancillary service value or a capacity payment. For this analysis Price $_{2, i}$ was considered to be fixed at 0 (because Texas has an energy-only market), but it could be considered in another analysis that looked at markets with capacity payments or the ability of solar PV to reduce demand changes for arrays behind the meter (many commercial and industrial customers have demand changes in addition to energy charges). This price would be appropriate to consider on a case by case basis, but is beyond the scope of this more general analysis. This calculation was then completed for multiple radiation inputs (measured, TMY, and clear-sky), weather inputs (measured and TMY), and pricing inputs (market and electric rate) for Austin.

\subsection{Optimal Solar Placement on a National Level}

The analysis was then generalized to a national level. TMY data were gathered and processed in the same way as described in Section 2.3 for 1,020 locations across the US [25]. The data were run through the solar placement value (Section 2.3) program in a similar fashion. However, to speed up the process, an optimization routine ( $R$ function optim, with method of Byrd et. al. [26]) was used so that each location's placements of both energy and value did not have to be directly computed. The optimization used a quasi-Newton method (L-BFGS-B), a version of the Broyden-Fletcher-Goldfarb-Shanno algorithm with box constraints [27]. The initial starting point was taken to be the local location's rule of thumb placement. The optimization reduced the solving time from 12 hours to less than 1 hour on a 16 core HPC. 
The expanded model considered both total energy produced, power produced, and the value of the produced energy. The energy-only model is the same as for the more Austin-specific analysis. However, the value of energy model was somewhat different. In order to consider the regional differences in electricity markets, local TOU energy rates were used as a proxy for the temporal value of energy, as it was assumed that these rates would be designed such that times of higher costs would be typically associated with times of higher grid stress/demand. An attempt was made to obtain an electric utility TOU rate for each state from the OpenEI database [24]. Of the 50 US states, at least 37 states had TOU rates for at least one customer class. When each simulation was run, the amount of energy produced during a given interval was multiplied by the rate for that hour. For all locations within a given state, a single representative rate from a large city in that state was used, for states without TOU rates, the closest (shortest Euclidian distance) to the nearest rate (by lat/long of largest city in each state) was used. However, when making recommendations for a specific location, using exact local data would yield the best results.

\subsection{Optimal Placement for Summer Peak Reduction}

The last step of the analysis was to explore the effects of solar placement on summer peak power reduction. The summer peak times are defined as June - August, from 14:00 - 20:00 CST for Austin, TX [28]. These times are typically associated with high wholesale electricity prices and grid stress, mainly due to residential air-conditioning load [29]. For this analysis the same approach was taken as with Equation 10, except the Price P $_{1, i}$ was given a value of 1 during summer peak hours and 0 otherwise. 


\section{Results and Discussion}

The following section discusses the results of the model and presents a discussion of the results and implications of this analysis for solar energy production.

\subsection{Calculating the value and effect of solar placement}

To verify that the entire process was running correctly, the model was first executed with clear-sky radiation. Because there is no clear-sky equivalent weather information available, TMY weather data (temperature, wind speed) were used. Using clear-sky as the radiation input should cancel out all weather shading effects to solar panel production and should indicate an optimal energy azimuth of due south and a tilt related to the local latitude (about $30^{\circ}$ for Austin). The model provided just that result, shown in Figure 2,

Table 1 summarizes the results of the various cases for both total energy production and the value of the energy produced in Austin, TX. For the cases where the placement was optimized for maximum total energy generated, the TMY case shifts the arrays about $8^{\circ}$ west of south. For the cases where the placement was optimized for maximum total economic value of the energy generated, the cases shift the arrays about 20 to $51^{\circ}$ west of south, depending on the price considered. While the increase in the amount of energy generated in the optimal cases was negligible, the increased economic values $\left(\$ / \mathrm{m}^{2} / \mathrm{yr}\right)$ for shifting the solar PV arrays west of south were on the order of 1-7\%.

Figure 2 shows the total number of $\mathrm{kWh}$ per year produced (normalized

for $1 \mathrm{~m}^{2}$ of array) for every combination of azimuth and tilt, $90^{\circ}-270^{\circ}$ and 
Table 1: Cases for for analysis of multiple radiation, weather, and economic data inputs for Austin, TX.

\begin{tabular}{|c|c|c|c|c|c|c|c|c|}
\hline $\begin{array}{l}\text { Radiation } \\
\text { Inputs }\end{array}$ & $\begin{array}{l}\text { Weather } \\
\text { Inputs }\end{array}$ & $\begin{array}{l}\text { Pricing } \\
\text { Data }\end{array}$ & $\begin{array}{l}\text { Optimal } \\
\text { Placement }\end{array}$ & Units & $\begin{array}{r}\text { Optimal } \\
\text { Value }\end{array}$ & $\begin{array}{l}\text { Value at } \\
180^{\circ} / 30^{\circ}\end{array}$ & $\begin{array}{l}\text { Percent } \\
\text { Change }\end{array}$ & $\begin{array}{r}\text { Figure } \\
\text { Reference }\end{array}$ \\
\hline Clear Sky & TMY & - & $180^{\circ} / 30^{\circ}$ & $\mathrm{kWh} / \mathrm{m}^{2} / \mathrm{yr}$ & 245.8 & 245.8 & 0.0 & Figure 2 \\
\hline TMY & TMY & - & $188^{\circ} / 28^{\circ}$ & $\mathrm{kWh} / \mathrm{m}^{2} / \mathrm{yr}$ & 156.3 & 156.0 & 0.2 & Figure 3 \\
\hline Measured & Measured & ERCOT AUCT & $204^{\circ} / 25^{\circ}$ & $\$ / \mathrm{m}^{2} / \mathrm{yr}$ & 5.94 & 5.85 & 1.6 & Figure 4 \\
\hline TMY & TMY & ERCOT AVG & $219^{\circ} / 29^{\circ}$ & $\$ / \mathrm{m}^{2} / \mathrm{yr}$ & 7.97 & 7.67 & 3.9 & Figure $\overline{5}$ \\
\hline TMY & TMY & AE TOU Rate* & $200^{\circ} / 25^{\circ}$ & $\$ / \mathrm{m}^{2} / \mathrm{yr}$ & 11.07 & 10.96 & 1.0 & Figure 6 \\
\hline TMY & TMY & ERCOT 2011 & $231^{\circ} / 30^{\circ}$ & $\$ / \mathrm{m}^{2} / \mathrm{yr}$ & 10.24 & 9.58 & 7.0 & Figure $\overline{7}$ \\
\hline
\end{tabular}

*Austin Energy residential time-of-use rate

$0^{\circ}-45^{\circ}$, respectfully using clear-sky radiation and TMY weather data.

Figure 3 shows the effect of using TMY radiation and weather on optimal placement. The number of kWhs overall are reduced compared to Figure 2 because this data include the effect of clouds on the amount of solar radiation that reaches the earth's surface. It is interesting to note that using 'typical meteorological' data for Austin indicates that shifting the array west $8^{\circ}$ and $2^{\circ}$ towards the horizontal (from the $180^{\circ} / 30^{\circ}$ rule-of-thumb) produces the most amount of energy, about $0.2 \%$ more than the rule-of-thumb. These results would suggest that meteorological events such as cloud cover in the mornings and winter typically block the sun more than in the afternoon and summer.

Figures 4 and 5 show the optimal azimuth for the value $\left(\$ / \mathrm{m}^{2} /\right.$ year $)$ of electricity produced (Equation 10) for the 2012-2013 measured data and coincident ERCOT prices and the TMY data with average ERCOT prices, respectfully. Both figures show that placement is shifted west when optimizing based on market value. 


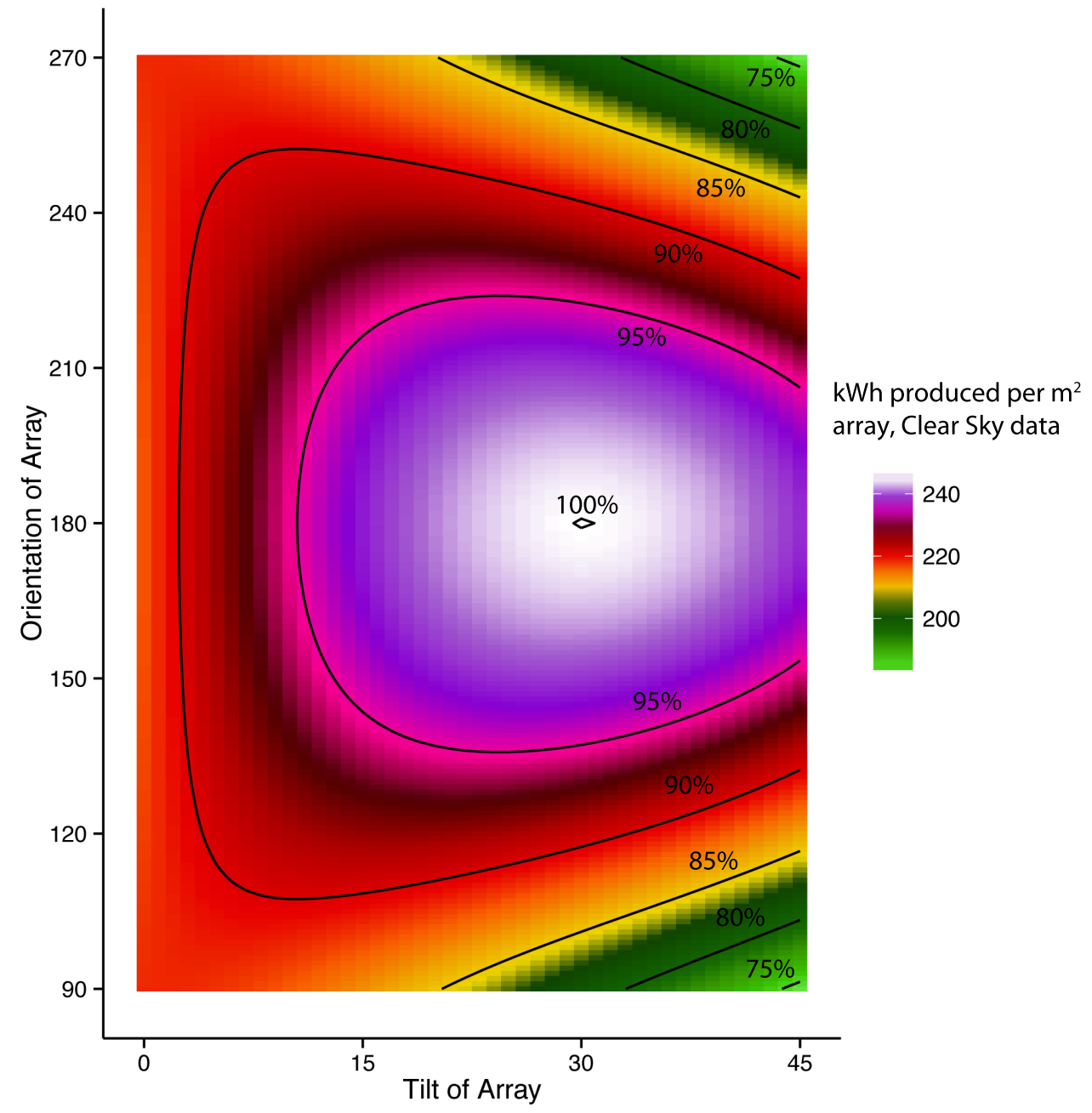

Figure 2: Heat map of model results for clear-sky radiation and TMY weather showing an optimal energy azimuth of $180^{\circ}$ and $30^{\circ}$ tilt, as expected for Austin, TX. Contour lines show areas of percent of maximum energy in $5 \%$ increments. 


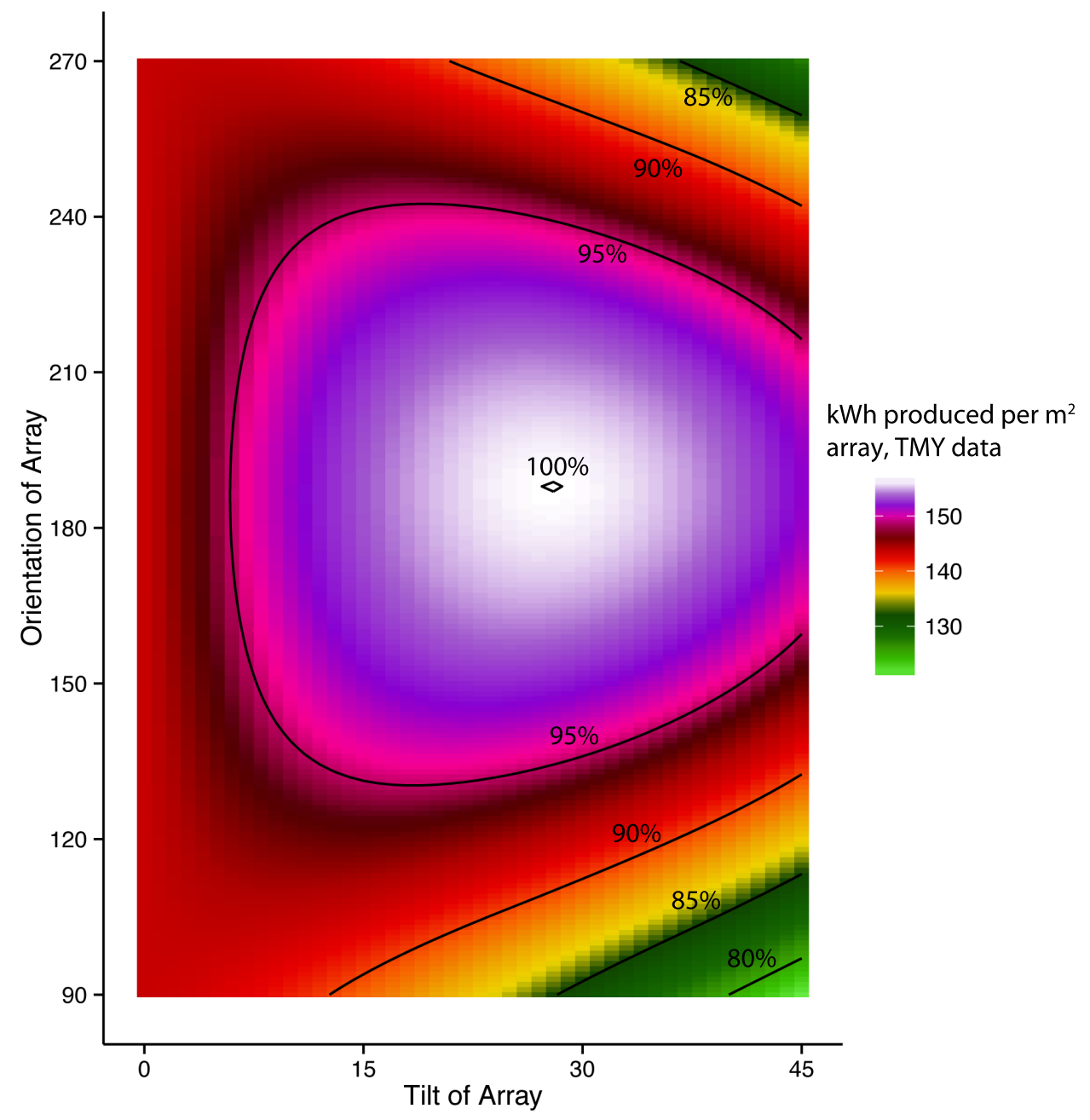

Figure 3: Heat map of model results for TMY radiation and TMY weather showing an optimal energy azimuth of $188^{\circ}$ and $28^{\circ}$ tilt, indicating the due south azimuth might not be optimal for total energy generation in Austin, TX when typical meteorological conditions are considered. Contour lines show areas of percent of maximum energy in $5 \%$ increments. 


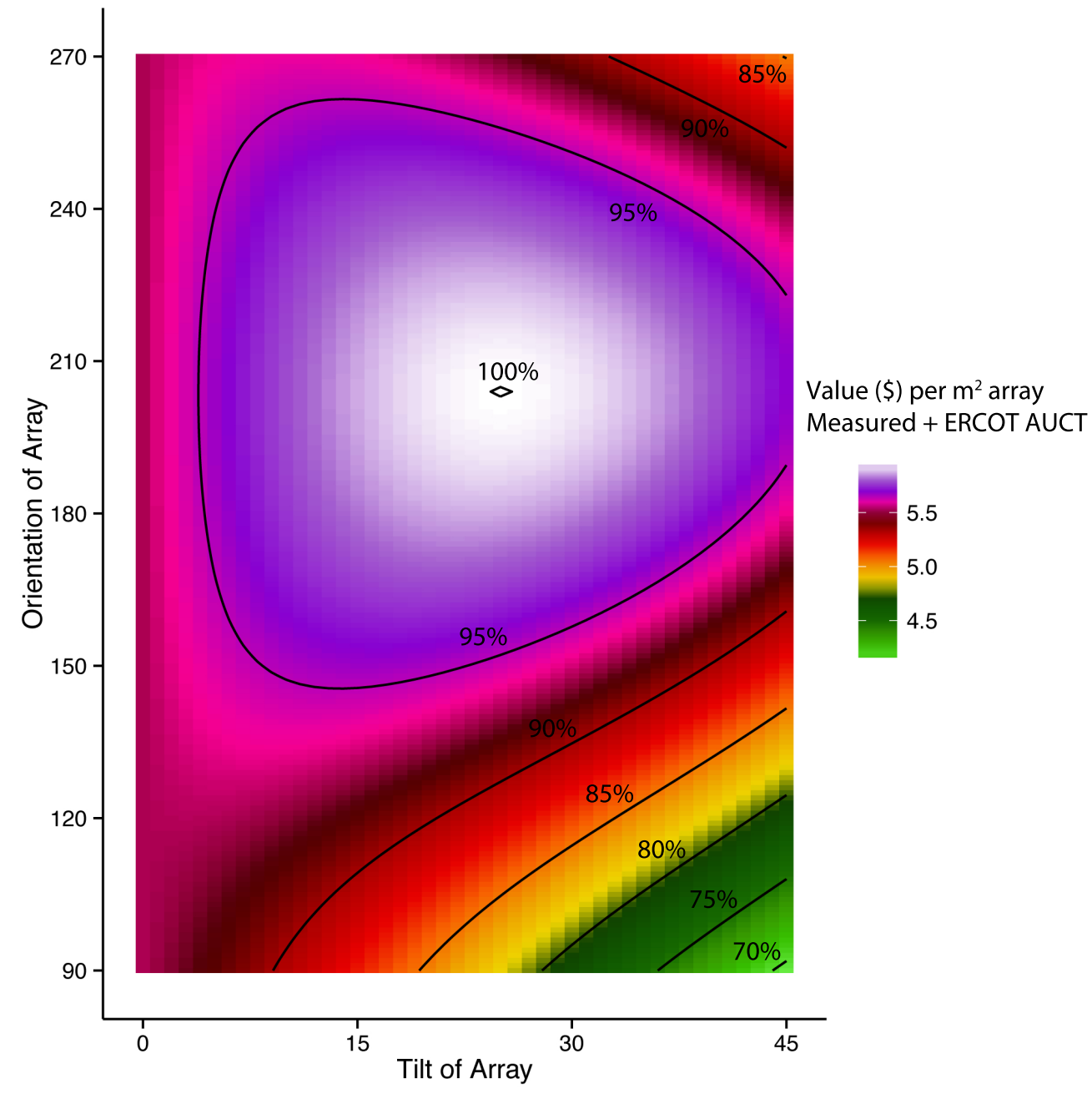

Figure 4: Heat map of model results for measured 2012-2013 radiation and weather with coincident ERCOT prices showing an optimal value $\left(\$ / \mathrm{m}^{2} /\right.$ year $)$ azimuth of $204^{\circ}$ and $25^{\circ}$ tilt for Austin, TX. Contour lines show areas of percent of maximum values in $5 \%$ increments. 


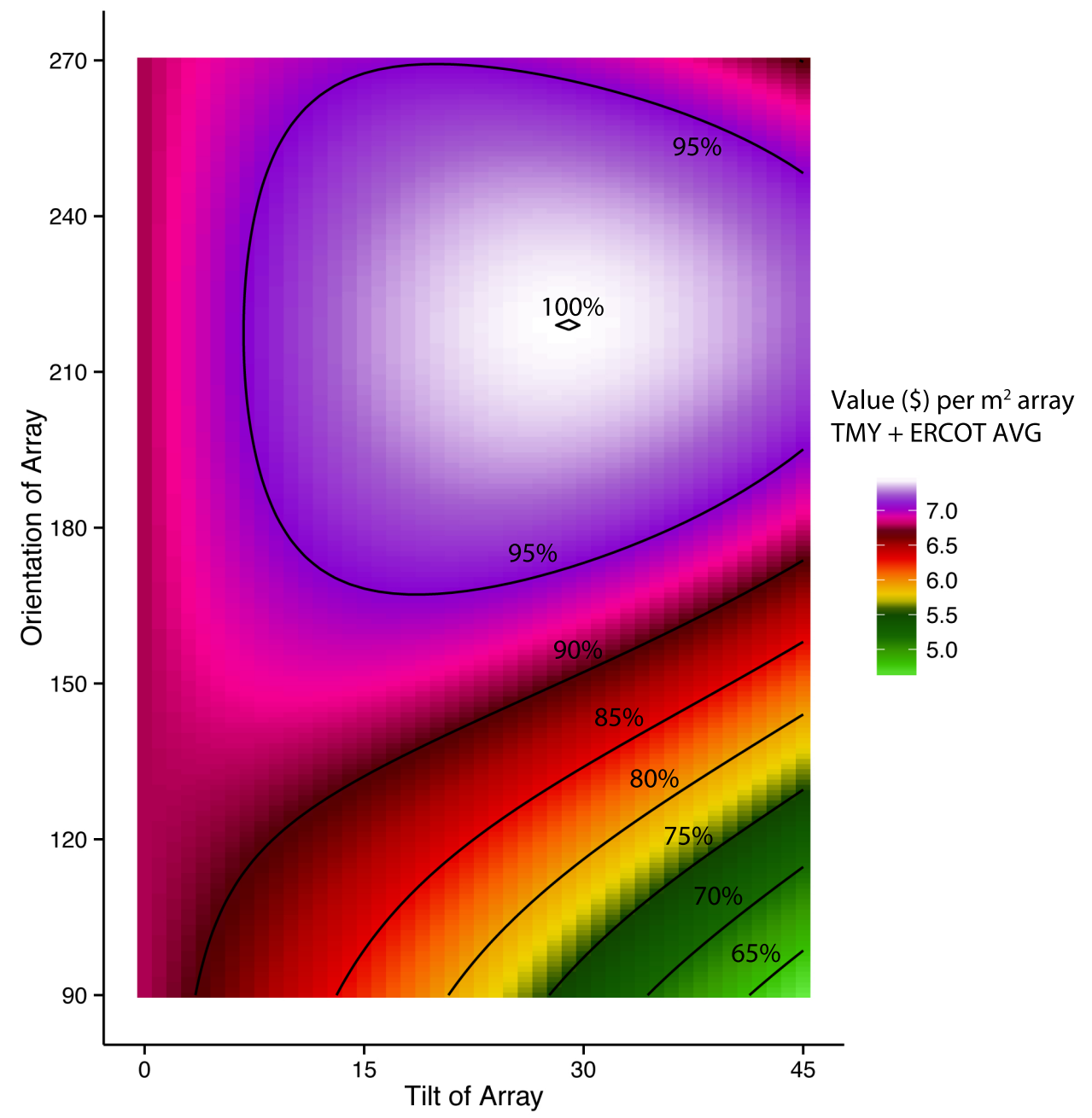

Figure 5: Heat map of model results for TMY radiation and weather with average ERCOT prices showing an optimal value $\left(\$ / \mathrm{m}^{2} /\right.$ year $)$ azimuth of $219^{\circ}$ and $29^{\circ}$ tilt for Austin, TX. Contour lines show areas of percent of maximum values in $5 \%$ increments. 
Figure 6 shows the values associated with Austin TMY solar radiation and weather with Austin Energy's residential TOU rate and also shows shows how azimuth and tilt are related under the TOU rate. For example, if a solar PV array's azimuth were constrained to $150^{\circ}$, its optimal tilt is not the $25^{\circ}$ associated with the unconstrained array, but $18^{\circ}$, a $0.5 \%\left(\$ / \mathrm{m}^{2} /\right.$ year $)$ difference.

Figure 7 shows the values associated with Austin TMY solar radiation and weather with ERCOT prices from 2011.

In general, higher summer electricity prices drive azimuth west and tilt towards the horizontal [10], as is seen in the Austin + TOU rate case. However, the later and the higher the electricity prices, the further the sun has dipped in the sky and the steeper the tilt will need to be to capture the incident radiation as seen in the TMY + ERCOT AVG and TMY + ERCOT 2011 cases. The TMY + ERCOT 2011 case is taken to be a scarcity pricing scenario as that year the price cap $(\$ 3000 / \mathrm{MWh})$ in ERCOT was hit for 54 15-minute periods, most after 16:00 local time, versus just once in 2012 and twice in 2013. However, the current price cap in ERCOT has been raised to $\$ 5000 /$ MWh with plans to further raise to $\$ 9000 /$ MWh. A high price cap and more instances of scarcity pricing (during historically consistent times of the day) could have an impact on the optimal placements of fixed solar PV installations, namely further west with a steeper tilt. Utilities could incentivize these solar placements as a hedge towards a more volatile wholesale electricity market. 


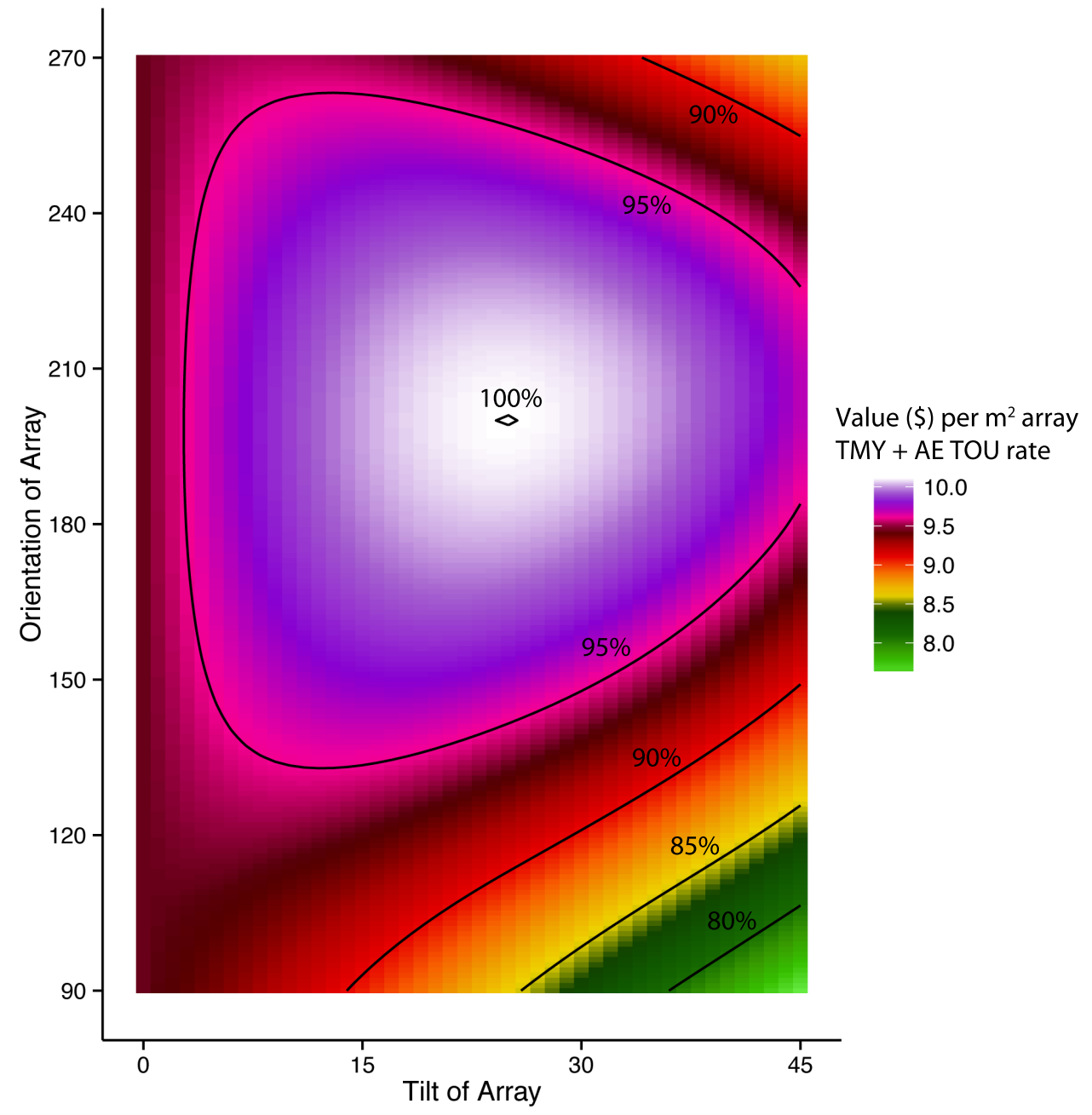

Figure 6: Heat map of model results for TMY radiation and weather with Austin Energy Residential TOU rate showing an optimal value $\left(\$ / \mathrm{m}^{2} /\right.$ year $)$ azimuth of $200^{\circ}$ and $25^{\circ}$ tilt for Austin, TX. Contour lines show areas of percent of maximum values in $5 \%$ increments. 


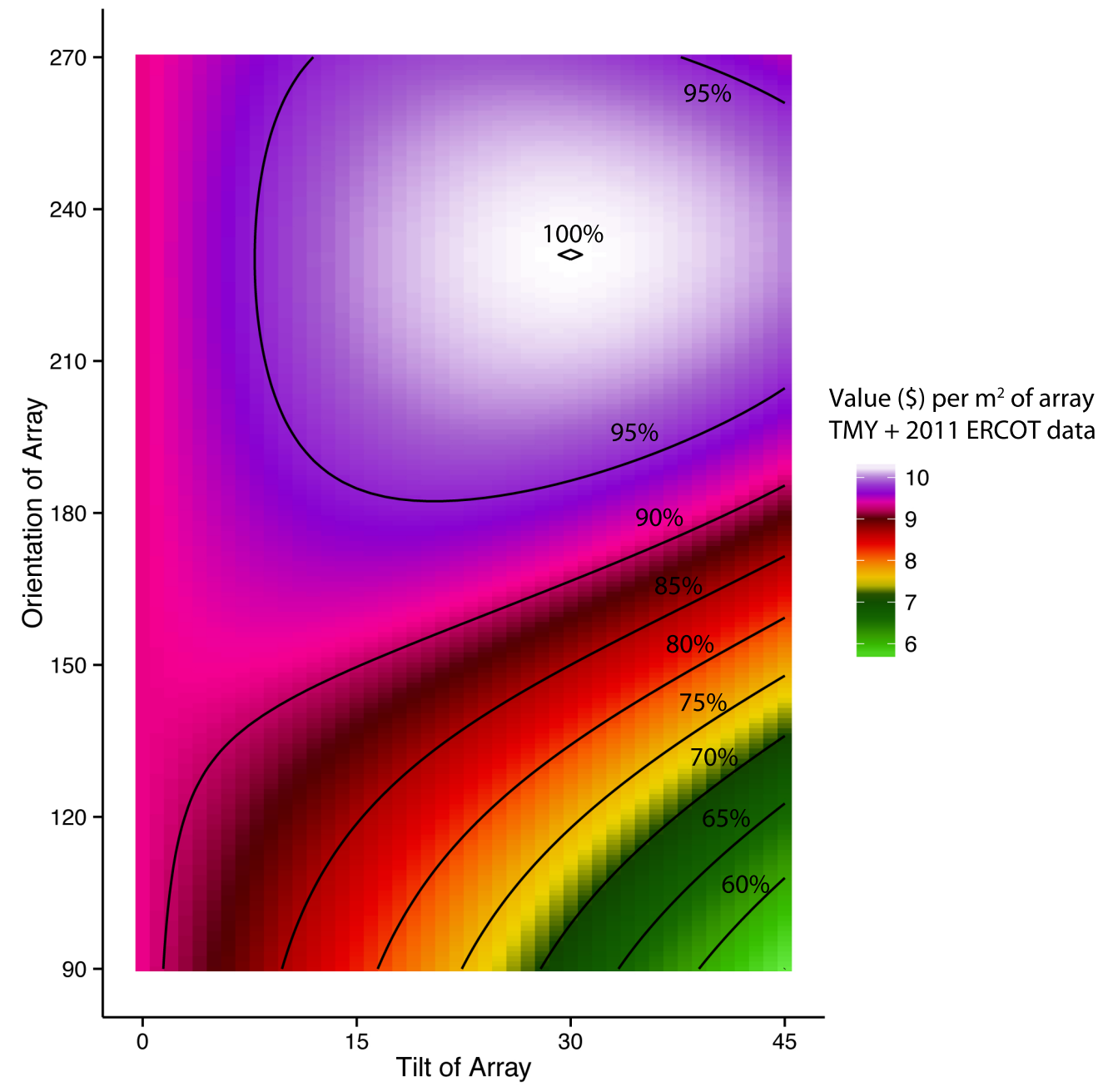

Figure 7: Heat map of model results for TMY radiation and 2011 ERCOT prices showing an optimal value $\left(\$ / \mathrm{m}^{2} /\right.$ year $)$ azimuth of $231^{\circ}$ and $30^{\circ}$ tilt for Austin, TX. Contour lines show areas of percent of maximum values in $5 \%$ increments. 


\subsection{Optimal Solar Placement on a National Level}

\subsubsection{Optimal azimuth}

The same analysis was performed on data from 1020 locations in the US that have TMY data. Figure 8 shows the results of the energy-only analysis.

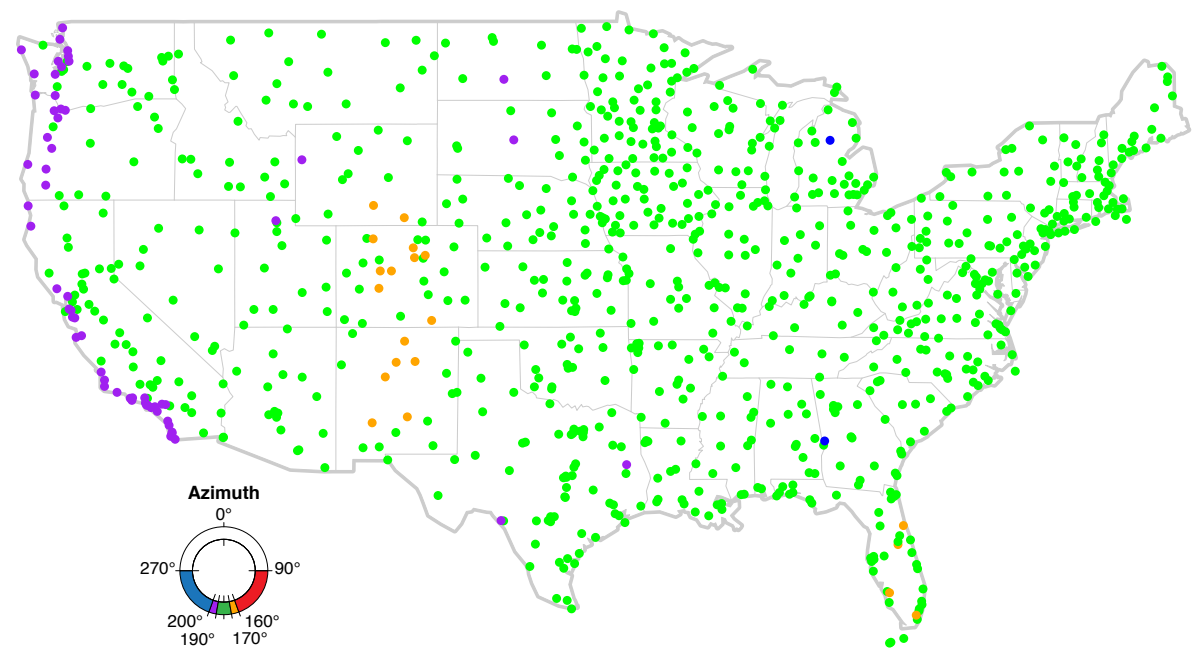

Figure 8: Map of continental US showing the energetically optimal azimuth of of solar PV systems. The red points indicate optimal solar azimuths east of south (less than $\left.160^{\circ}\right)$, orange points indicate southerly optimal solar azimuths $\left(160^{\circ}-170^{\circ}\right)$, green points indicate southerly optimal solar azimuths $\left(170^{\circ}-190^{\circ}\right)$, purple points indicate slightly west of south optimal solar azimuths $\left(190^{\circ}-200^{\circ}\right)$, and blue points indicate optimal azimuths west of south (greater than $200^{\circ}$ ).

com

that a band of locations from Wyoming, through Colorado, and into New 
Mexico have optimal azimuths that face east of south. This result is probably explained in that these locations are along the Rocky Mountains and have prevailing summer afternoon thunderstorms. Another location of interest the US west coast, where the model indicates an optimal west-facing azimuth for almost the entire length of the coast. This effect is probably explained by persistent cloudiness in the early part of the day. Similar results have been observed in earlier studies as well [10, 15].

These findings are significant because Colorado ranks $10^{\text {th }}(130 \mathrm{MW})$ in the US for installed solar capacity and California ranks $1^{\text {st }}$ at 2,051 MW (Texas ranks $7^{\text {th }}$ at $174 \mathrm{MW}$ ) [30]. While data on the actual placements of solar PV systems are not readily available, if roughly half of California's small scale $(<25 \mathrm{~kW}$ capacity) solar output could be improved $1 \%$ via an optimal placement, the result would be an additional production of approximately 15 million $\mathrm{kWh} /$ year at current capacity levels - about the total annual electricity consumption of 2,200 California homes [31].

Figure 9 shows the results when considering the maximum economic value of the solar energy produced for all considered solar placements. Again, the value of the electricity produced is approximated by the structure of a utility TOU pricing structure that is either in the state of the TMY data location, or if the state doesn't have a TOU rate available, the closest location with a TOU rate was chosen.

Overall the economic consideration shifts the number of optimally southfacing $\left(170^{\circ}-190^{\circ}\right)$ array locations from 920 (pure energy analysis) to 477 locations. The number of slightly west-facing $\left(190^{\circ}-200^{\circ}\right)$ array locations increased from 62 to 234, the number of further west-facing arrays (greater 


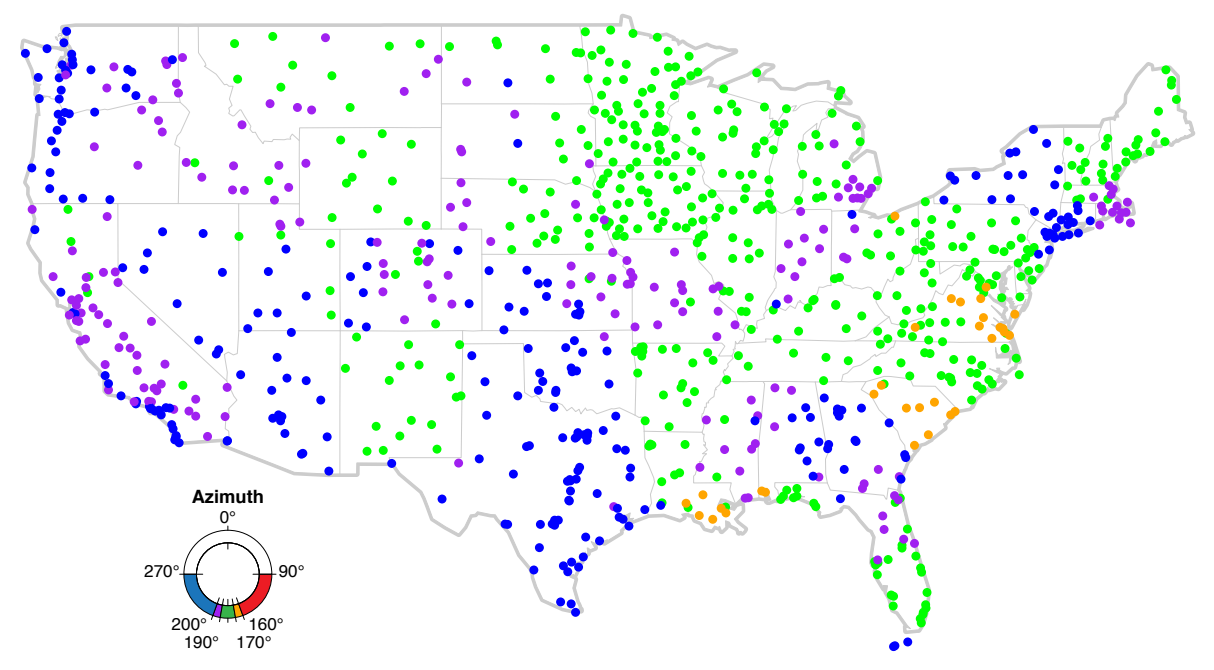

Figure 9: Map of continental US showing optimal azimuth of solar PV systems when considering the value of the solar energy produced. The red points indicate optimal solar azimuths east of south (less than $160^{\circ}$ ), orange points indicate southerly optimal solar azimuths $\left(160^{\circ}-170^{\circ}\right)$, green points indicate southerly optimal solar azimuths $\left(170^{\circ}-\right.$ $\left.190^{\circ}\right)$, purple points indicate slightly west of south optimal solar azimuths $\left(190^{\circ}-200^{\circ}\right)$, and blue points indicate optimal azimuths west of south (greater than $200^{\circ}$ ). 
than $\left.200^{\circ}\right)$ increased from 2 to 264 , the number of slightly east-facing $\left(160^{\circ}-\right.$ $170^{\circ}$ ) array locations increased from 36 to 45 . However, because the rates were not the same, the change of optimal economic placement is different for different locations. A significant portion of the western half of the US, including Texas shifted west. Even some arrays that had an optimal energy placement east of south in Colorado trended west. The eastern half of the US, which for energy only was almost all south-facing is more mixed. For example, the TOU rates of Virginia and South Carolina, while they have higher summer afternoon prices, also have high morning prices in the winter months, presumably due to a morning grid peak from electrical heating or activity demand. Other states, such as New York, had rate structures that reflect higher afternoon grid demand.

\subsubsection{Optimal Tilt}

While best practices would have tilts of solar systems determined by local solar data as is attempted in this analysis, many times the tilt is decided based on the local latitude alone [8]. Figure 10 shows the deviation from the rule of thumb (i.e. local latitude) for optimal energetic tilt in each location.

Figure 10 suggests that while accurate for parts of the southwest US, the optimal energy tilt is typically lower than the local latitude, especially in the states surrounding Tennessee and Kentucky. Lower optimal tilts would indicate the prevalence of more sunny days when the sun is higher in the summer sky. Figure 11 shows a map of the deviation from the rule of thumb tilts as determined by the maximum value $\left(\$ / \mathrm{m}^{2} /\right.$ year based on local TOU electric rates) of the solar energy produced.

Figures 10 and 11 are very similar, except in situations where the local 


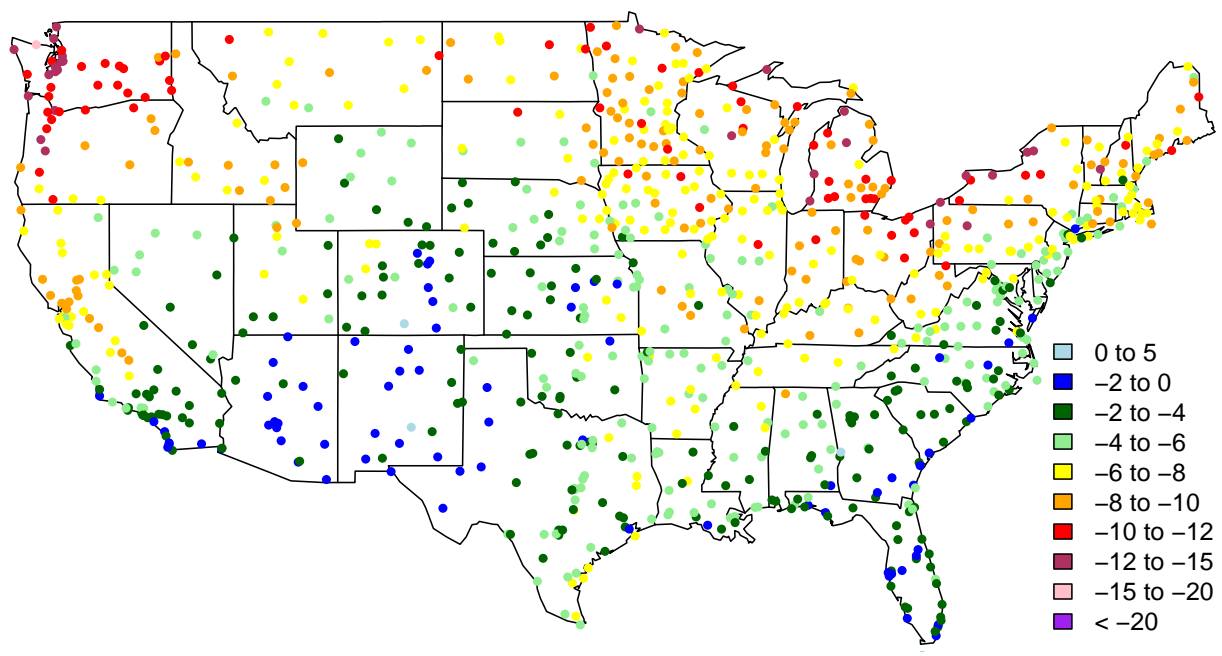

Figure 10: Map of continental US showing deviation from the rule of thumb tilt (local latitude) based on total energy production. Negative values mean that the optimal tilt is below the local latitude. 


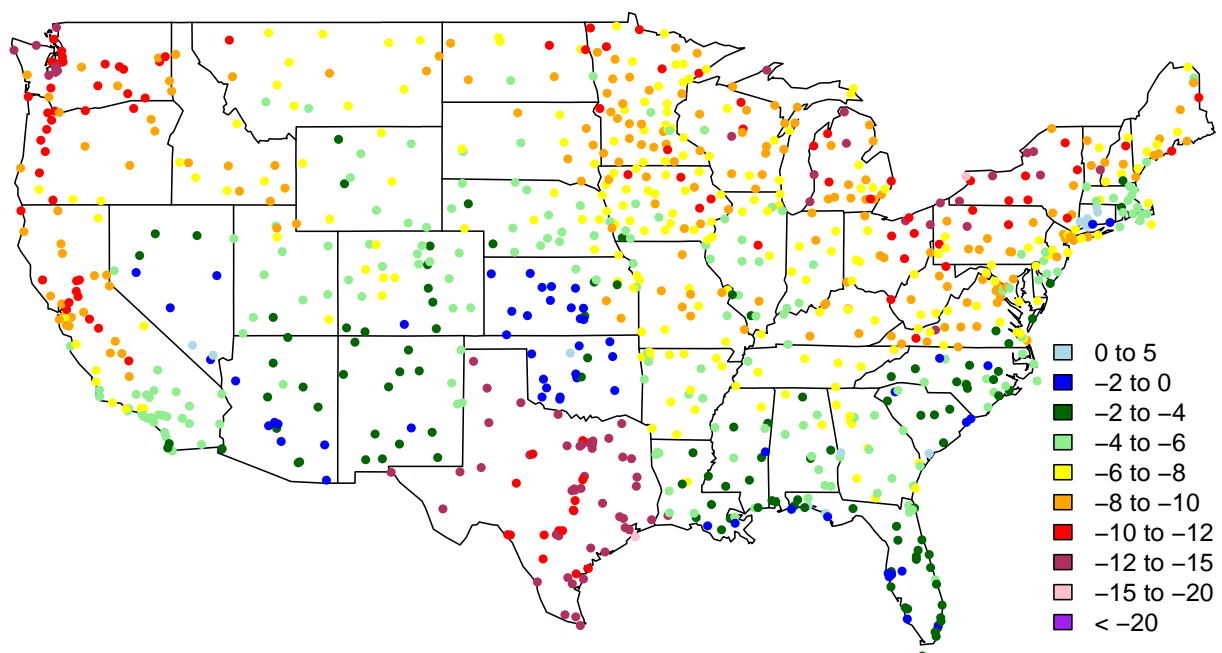

Figure 11: Map of continental US showing deviation from the rule of thumb tilt (local latitude) based on the value of local energy production. Negative values mean that the optimal tilt is below the local latitude. 
rates incentivize either more summer or winter production. For example, in California, high summer afternoon electricity prices force the optimal tilt lower to produce more during the summer peak.

\subsection{Optimal Azimuth and Tilt to Align with Summer Peak Demand}

To understand how solar PV systems should be placed if the goal were to generate as many kWh during summer peak hours as possible, the analysis was run again where the value of solar was only considered during the afternoon summer hours. This portion of the analysis restricted the time of interest to June through August, and between 14:00 to 20:00 - a time period typically associated with high electric grid stress times and higher wholesale electricity prices. For Austin, as well as for most of the US, the optimal peak array placement was shifted due west. The average peak optimal azimuth was $266^{\circ}$ with a standard deviation of $6.4^{\circ}$ and the average optimal peak tilt was $51^{\circ}$ with a standard deviation of $4.6^{\circ}$. Figure 12 shows the average generation curves for various solar placements in Austin using TMY data, including optimal peak placement. The top part of Figure 12 shows the generation curves for the entire year and the lower part shows the curves for only the summer months (June - August). Table 2 summarizes the differences in energy produced (area under the curves) from the placements shown in Figure 12 .

For Austin, the optimal energy and optimal value placements do not differ much from south placements in terms of energy use. However, westfacing and optimal peak placement generate about 14 and 20\% less energy throughout the year. In the summer, the optimal energy, optimal value, and the west-facing array generate about the same amount of energy as the south- 

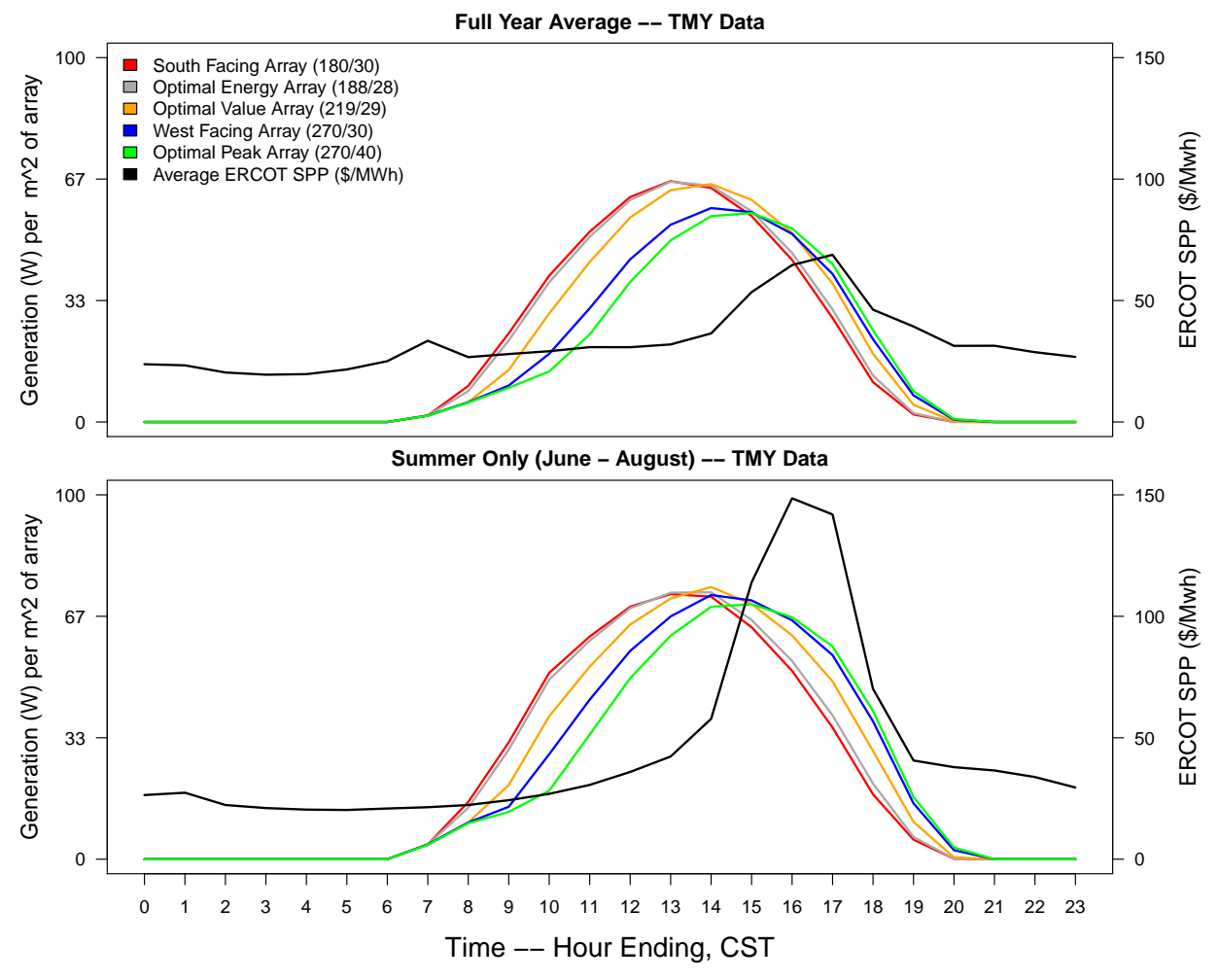

Figure 12: Plot showing the average generation profiles of solar PV systems at various placements in Austin, TX and the average ERCOT SPP for the same time period (Section Appendix A. 
Table 2: Percent change in amount of energy generated and the value of energy generated (considering Austin's TOU rate) by various solar PV placements as compared to a south facing $\left(180^{\circ} / 30^{\circ}\right)$ array for an entire year, only the summer months (July - August), and for just the peak hours during the summer months (14:00 - 20:00) for Austin, TX.

\begin{tabular}{lrrr|r}
\hline Placement & Full year & Summer only & $\begin{array}{r}\text { Summer peak } \\
\text { hours only }\end{array}$ & $\begin{array}{r}\text { Value of } \\
\text { energy }\end{array}$ \\
\hline South-Facing $\left(180^{\circ} / 30^{\circ}\right)$ & 0.00 & 0.00 & 0.00 & 0.00 \\
Optimal Energy $\left(188^{\circ} / 28^{\circ}\right)$ & 0.17 & 1.13 & 5.00 & 0.71 \\
Optimal Value Placement $\left(219^{\circ} / 29^{\circ}\right)$ & -1.86 & 0.88 & 16.44 & 0.93 \\
West-Facing Placement $\left(270^{\circ} / 30^{\circ}\right)$ & -14.32 & -1.34 & 23.04 & -7.70 \\
Optimal Peak Placement $\left(270^{\circ} / 40^{\circ}\right)$ & -19.55 & -7.20 & 24.07 & -11.12 \\
\hline
\end{tabular}

facing array with the optimal peak array generating less. During the summer peak demand hours, all placements generate more energy than south-facing arrays with west and optimal peak placements generate 23 and $24 \%$ more energy during peak hours, respectfully. The differences in the value of energy for Austin's TOU rate increase to the optimal value array, but then fall as the placement moves further west. However, this assessment is contingent on the economics considered and these numbers would differ for other rates or ERCOT prices.

\section{Conclusions}

This analysis considers the the effect of various placements (azimuth and tilt) of solar PV systems on energy generation and value of that energy generation for a yearly period with various environmental and economic inputs 
in Austin, TX and many locations across the US. The results are generally consistent with previous studies on optimal solar placement. However, this analysis extends the body of knowledge by considering the AC electricity produced from a typical solar PV system and by considering electricity prices on a national scale. These results show how local electricity markets (as seen through TOU prices) affect the economic value of solar placement on a national level.

These results have the potential to be significant for solar PV installations. However, the definition of optimal solar PV placement (especially the optimal economic placement) might vary based on whom the definition is asked. Large ground-mounted and flat roof arrays that require fixtures could possibly take advantage of an optimal placement (or perceived future optimal placement) at little to no additional cost than due south installations. For a building of fixed orientation, a cost-benefit analysis would have to consider possible less capacity (due to solar PV installations not being aligned with the building lines) verses temporal generation revenue. Utilities can encourage this optimal placement (which could be further west than arrays designed to maximize energy production) by structuring rates that offset their highest wholesale cost times and net-metering or similarly through a 'time-of-production' buying rate for solar energy production. Also, these results could be used to influence roof azimuth and pitch in new construction or retrofits to maximize the ability of installed solar PV systems to generate energy.

While the solar tilt rule-of-thumb for total energy production might be a good approximation for most of the US, it does not apply everywhere. No- 
table examples include some locations east of the front range (Rocky Mountains) and the majority of the west coast. Using local TOU electricity rates as a proxy for local grid conditions further changes the optimal tilt. In many locations, the optimal tilt is shifted down, particularly in locations that have TOU rates with higher summer afternoon prices. Although in some cases, rates shift the tilt steeper - particularly in places where TOU rates are high in winter times.

In Austin, TX (for total energy production), TMY data indicate a $8^{\circ}$ shift west $\left(188^{\circ}\right.$ ) and a few degrees towards the horizontal (from the rule-of-thumb $30^{\circ}$ ) might be a better azimuth and tilt for energy production. Clear sky radiation data reinforce the energy rule-of-thumb as expected. Considering the value of energy produced, the optimal azimuth was pushed further west $\left(\approx 20-51^{\circ}\right)$ based on wholesale electricity market prices that are typically higher in the mid to late afternoon hours. While the resulting improvements might might seem small, ( $<1-7 \%$ difference), the improvement could be free to implement during construction, and over the 25 year lifespan the excess energy produced and revenue earned could be significant.

\section{Acknowledgments}

The authors would like to thank the the Department of Energy, Austin Energy, and Pecan Street Inc. for their direct and in-kind support. The authors would also like to thank the study participants and the Mueller neighborhood groups for their support. A special thanks to The State Environmental Conservation Office of Texas (SECO) and the University of Texas at Austin Green Fee Committee for their support of the SWEAT Lab. Another 
special thanks to the Texas Advanced Computing Center for computing support on the Stampede supercomputing system (NSF award OCI-1134872), as well as David Walling for his direct assistance.

This material is based partly upon work supported by the National Science Foundation Graduate Research Fellowship under Grant No. DGE1110007. Any opinion, findings, and conclusions or recommendations expressed in this material are those of the authors and do not necessarily reflect the views of the National Science Foundation.

\section{Disclosure of Affiliation}

In addition to research work on topics generally related to energy systems at the University of Texas at Austin, some of the authors are equity partners in IdeaSmiths LLC, which consults on topics in the same areas of interests. The terms of this arrangement have been reviewed and approved by the University of Texas at Austin in accordance with its policy on objectivity in research.

\section{Appendix A. Data Collection and Preparation}

The data used in this analysis include 1) real-world solar insolation (global and diffuse horizontal) and weather data, measured in 1-minute increments in Austin, TX from July 2012 to June 2013, 2) simulated 1-minute clearsky radiation calculations for Austin (i.e. the amount of solar radiation that would exist in the total absence of any type of weather that would block or amplify actual radiation), 3) 1-minute solar PV output from residential solar PV systems in Austin, 4) 15-minute electricity market Settlement Point 
Price (SPP) data from the Electric Reliability Council of Texas (ERCOT), the state-wide electric grid of Texas, 5) 1-hour Typical Meteorological Year (TMY) solar and weather data, and 6) a representative sampling of utility time-of-use (TOU) electric rates from across the US. The measured solar radiation and weather data were collected at the SWEAT Lab (Solar, Water, Energy and Thermal Lab) [32], on the roof a a 10-story building on The University of Texas at Austin main campus 33. The clear-sky radiation measurements were calculated using Master's equations [34]. The solar PV output data are part of the Pecan Street Smart Grid Demonstration Project [33], the archived pricing data are available from ERCOT [35], and the utility rates were collected from the OpenEI utility rate database [24]. The TMY3 weather data are from files created by the National Renewable Energy Lab (NREL) to serve as standardized input weather data for energy simulation programs and statistically represent a 'typical' year for the specified location.

Because this analysis is temporal in nature, and many different datasets were merged together, great care was taken to convert timestamps to a single common form. For example, the measured solar radiation data were collected with a UTC timestamp, the solar PV generation values were collected with a 'local time' timestamp that accounted for daylight savings, TMY data are collected in a 'local time' timestamp that does not account for daylight savings time, and utility rate data were collected with a 'local time' timestamp that accounted for daylight savings. Also, accounting for the interval collection method of each dataset was very important. For instance the solar data are collected in an 'interval beginning' fashion such that the value for 
14:00 is the average of all the data points collected from 14:00 - 14:59, and the TMY data are in 'interval ending' such that the value for 16:00 is the average of measurements collected in the 15:01 - 16:00 period. For simplicity all timestamps were converted to Coordinated Universal Time (UTC) which is the standard by which timezones are set.

Since even 1-hour can make a difference in the results of this analysis, datasets that were only available with 1-hour increments (i.e. TMY and utility rate data) were first corrected to not include daylight savings (if it was accounted for) and then 30 minutes was subtracted or added from each timestamp to 'centralize' the timestamp in the middle of its interval. The 1-minute data were not centralized because of their much higher reporting frequency. 


\section{References}

[1] Carbon Footprint of Electricity Generation. Tech. Rep.; UK_POST; 2011. URL: http://www.parliament.uk/documents/post/postpn_ 383-carbon-footprint-electricity-generation.pdf.

[2] EIA, . Monthly Energy Review - May 2012; 2012. URL: http://www. eia.gov/totalenergy/data/monthly/archive/00351205.pdf

[3] IPCC, . Climate Change 2013: The Physical Science Basis. Working Group I Contribution to the IPCC 5th Assessment Report - Changes to the Underlying Scientific/Technical Assessment; 2013. URL: http: //www .ipcc.ch/report/ar5/wg1/\#.UqT0mGRDu8E.

[4] EIA, . Updated Capital Cost Estimates for Utility Scale Electricity Generating Plants. Tech. Rep.; U.S. Department of Energy; Washington, DC; 2013. URL: http://wwW.eia.gov/forecasts/capitalcost/pdf/ updated_capcost.pdf.

[5] Singh, A.K., Parida, S.K.. Need of Distributed Generation for Sustainable Development in Coming Future. In: IEEE International Conference on Power Electronics, Drives and Energy Systems (PEDES 2012). Bengaluru, India: IEEE; 2012,URL: http://apps.webofknowledge.com.ezproxy.lib.utexas.edu/ full_record.do?product=WOS\&search_mode=GeneralSearch\&qid=3\& SID=4FqqAglRLX1j1esnOzl\&page $=5 \& d o c=46$.

[6] Salvatore, J.. Sustainable Energy in America 2013 Fact- 
[7] EIA, . Assumptions to the Annual Energy Outlook 2013. Tech. Rep. January; 2013. URL: http://www.eia.gov/forecasts/aeo/pdf/ 0383(2013) .pdf.

[8] Yadav, A.K., Chandel, S.. Tilt angle optimization to maximize incident solar radiation: A review. Renewable and Sustainable Energy Reviews 2013;23:503-513. URL: http://www.sciencedirect. com/science/article/pii/S1364032113001299.

[9] Christensen, C.B., Barker, G.M.. Effects Of Tilt And Azimuth On Annual Incident Solar Radiation For United States Locations. In: Solar Forum 2001. Washington, DC; 2001,.

[10] Lave, M., Kleissl, J.. Optimum fixed orientations and benefits of tracking for capturing solar radiation in the continental United States. Renewable Energy 2011;36(3):1145-1152. URL: http://www. sciencedirect.com/science/article/pii/S0960148110003964.

[11] Stultz, J.W.. Thermal and Other Tests of Photovoltaic Modules Performed in Natural Sunlight. Journal of Energy 1979;3(6):363-372. URL: http://www.osti.gov/energycitations/product.biblio.jsp? osti_id=6418708http://arc . aiaa.org/doi/abs/10.2514/3.62445. doi:doi:10.2514/3.62445.

[12] McCracken, B., Fisher, G., Hersey, A., Shead, J., Sokolic, K.. 
Residential solar systems reduce summer peak demand by 58 percent in Texas research trial; 2013.

[13] Rowlands, I.H., Kemery, B.P., Beausoleil-Morrison, I.. Optimal solarPV tilt angle and azimuth: An Ontario (Canada) case-study. Energy Policy 2011;39(3):1397-1409. URL: http://www.sciencedirect.com/ science/article/pii/S0301421510008931.

[14] Schroder, A.. Determination of annual optimal altitude and azimuth angles of fixed tilt solar collectors in the continental United States using the National Solar Radiation Database. In: Proceedings of the ASES National Solar Conference. 2011,.

[15] Luoma, J., Lave, M., Kleissl, J.. Optimum fixed orientations considering day-ahead market energy pricing in California. In: American Solar Energy Society Conference. Denver, CO; 2012, p. 1-5.

[16] Hay, J.J.E., McKay, D.D.C.. Estimating solar irradiance on inclined surfaces: a review and assessment of methodologies. International Journal of Solar Energy 1985;3(4-5):203-240. URL: http://www . tandfonline.com/doi/abs/10.1080/01425918508914395. doi:doi:10. 1080/01425918508914395.

[17] Duffie, J.A., Beckman, W.A.. Solar Engineering of Thermal Processes. 3rd ed.; Wiley; 2006. ISBN 0471698679.

[18] Perpiñán, O.. solaR: Solar Radiation and Photovoltaic Systems with R. Journal of Statistical Software 2012;50(9):1-32. 
[19] Hay, J., Davies, J.. Calculations of the solar radiation incident on an inclined surface. In: Proc. of the First Canadian Solar Radiation Data Workshop. Canada: Ministry of Supply and Services; 1980,.

[20] Reindl, D., Beckman, W., Duffie, J.. Evaluation of hourly tilted surface radiation models. Solar Energy 1990;45(1):9-17. URL: http: //linkinghub.elsevier.com/retrieve/pii/0038092X9090061G. doi:doi:10.1016/0038-092X(90)90061-G.

[21] Skoplaki, E., Palyvos, J.. On the temperature dependence of photovoltaic module electrical performance: A review of efficiency/power correlations. Solar Energy 2009;83(5):614-624. URL: http://linkinghub. elsevier.com/retrieve/pii/S0038092X08002788, doi:doi:10.1016/j. solener.2008.10.008.

[22] Power-one, . AURORA UNO Photovoltaic Inverters Technical Manual. Tech. Rep.; 2013. URL: http://www.power-one.com/sites/ power-one.com/files/documents/renewable-energy/tech-manual/ pvi-5000_6000-outd-us-technical_manual_na_2.2.pdf.

[23] Lumos, . Lumos LS 250 Series. Tech. Rep. 3; 2012. URL: http: //www. lighthousesolar.com/content/pdf/LS250-60M-B.pdf.

[24] Utilities - Open Energy Information. 2013. URL: http://en.openei. org/wiki/Gateway:Utilities.

[25] Wilcox, S., Marion, W.. Users Manual for TMY3 Data Sets; 2008. URL: http://www.nrel.gov/docs/fy08osti/43156.pdfhttp: 
//www.doe2.com/download/weather/TMY3/Users_Manual_for_TMY3_ Data_Sets.pdf.

[26] Byrd, R.H., Lu, P., Nocedal, J., Zhu, C.. A Limited Memory Algorithm for Bound Constrained Optimization. SIAM Journal on Scientific Computing 1995;16(5):1190-1208. URL: http://epubs.siam. org/doi/abs/10.1137/0916069. doi:doi:10.1137/0916069.

[27] Nocedal, J., Wright, S.. Numerical Optimization. 2nd ed.; Springer; 2006. URL: http://www.springer.com/mathematics/book/ 978-0-387-30303-1.

[28] City of Austin Electric Rate Schedules. 2013. URL: http: //www .austinenergy.com/aboutus/rates/pdfs/Residential/ ResidentialAustin.pdf.

[29] Doggett, T.. Overcoming Barriers to Smart Grids \& New Energy Services Electric Reliability Council of Texas. In: UT Smart Grid Conference. Austin; 2011,.

[30] National Renewable Energy Lab, . The OpenPV Project. 2013. URL: https://openpv.nrel.gov/gallery.

[31] EIA, . How much electricity does an American home use? - FAQ - U.S. Energy Information Administration (EIA). 2013. URL: http://www . eia.gov/todayinenergy/detail.cfm?id=9911http: //www.eia.gov/tools/faqs/faq. $c f m ? i d=97 \& t=3$.

[32] SWEAT Lab — Webber Energy Group. 2013. URL: http://www. webberenergygroup.com/solar/. 
579 [33] Rhodes, J.D., Upshaw, C.R., Harris, C.B., Meehan, C.M., ${ }_{580}$ Walling, D.A., Navrátil, P.A., et al. Experimental and data collec581 tion methods for a large-scale smart grid deployment: Methods and 582 first results. Energy 2014;65:462-471. URL: http://linkinghub. 583 a elsevier.com/retrieve/pii/S0360544213009663. doi:doi:10.1016/j. 584 energy.2013.11.004.

585 [34] Masters, G.M.. Renewable and Efficient Electric Power Systems. 1 586 a ed.; Wiley-IEEE Press; 2004. ISBN 0471280607. URL: http://ww. 587 amazon.com/Renewable-Efficient-Electric-Power-Systems/dp/ $588 \quad 0471280607$.

589 [35] ERCOT Market Prices. 2013. URL: http://ercot.com/mktinfo/ 590 prices/index. 